\title{
Design of a wind turbine swept blade through extensive load analysis
}

\author{
Pavese, Christian; Kim, Taeseong; Murcia, Juan Pablo
}

Published in:

Renewable Energy

Link to article, DOI:

10.1016/j.renene.2016.10.039

Publication date:

2017

Document Version

Peer reviewed version

Link back to DTU Orbit

Citation (APA):

Pavese, C., Kim, T., \& Murcia, J. P. (2017). Design of a wind turbine swept blade through extensive load analysis. Renewable Energy, 102(Part A), 21-34. https://doi.org/10.1016/j.renene.2016.10.039

\section{General rights}

Copyright and moral rights for the publications made accessible in the public portal are retained by the authors and/or other copyright owners and it is a condition of accessing publications that users recognise and abide by the legal requirements associated with these rights.

- Users may download and print one copy of any publication from the public portal for the purpose of private study or research.

- You may not further distribute the material or use it for any profit-making activity or commercial gain

- You may freely distribute the URL identifying the publication in the public portal

If you believe that this document breaches copyright please contact us providing details, and we will remove access to the work immediately and investigate your claim. 


\title{
Design of a Wind Turbine Swept Blade Through Extensive Load Analysis
}

\author{
Christian Pavese*, Taeseong Kim*, Juan Pablo Murcia* \\ *Technical University of Denmark, Department of Wind Energy - DTU Risø Campus, 4000 Roskilde, \\ Denmark. \\ cpav@dtu.dk
}

\begin{abstract}
The main focus of this work is to offer an extensive investigation regarding the use of backward swept blades for passive load alleviation on wind turbines. Sweeping blades backward produces a structural coupling between flapwise bending towards the tower and torsion towards feathering. This coupling mitigates loads on the wind turbine structure due to a decrease in the angle of attack. The load alleviation can be achieved by changing the blade geometry according to three parameters: starting point for the change of shape along the blade span, blade tip sweep, and blade forward sweep. A parametric study is carried out on a $10 \mathrm{MW}$ wind turbine with the purpose of outlining the relation between load variations and three geometric parameters used to introduce passive control on wind turbine blades. The objective is to estimate and analyze extreme and fatigue loads, formulating suggestions for the design of a wind turbine that employs backward swept blades. From the investigation, it is concluded that mildly and purely backward swept shapes are the best option because they allow the wind turbine to achieve load alleviations without a large increase of the blade root torsional extreme and life-time equivalent fatigue moment. The efficacy of the design procedure provided with this work is proved through its application on a $5 \mathrm{MW}$ wind turbine design.
\end{abstract}

Keywords: Wind Energy, Blade Design, Passive Load Alleviation 
this end, different techniques have been exploited in the last two decades to achieve load reduction on wind turbines, and they can be generally categorized in two branches: active and passive control methods. The first consists of technologies able to reduce loads by actively controlling the machine, e.g. blade pitch actuators [4, moving flaps [5], etc. The second is based on the idea of designing a structure that, without any additional components, deforms so as to induce a load reduction when it is loaded [6]. The work presented in this paper focuses only on passive control methodologies and, in particular, on the employment of swept blades. Sweeping blades backwards is considered a load alleviation technique. This methodology produces a structural coupling between flapwise bending towards the tower and torsion towards feathering. This coupling mitigates loads on the wind turbine structure due to a decrease in the angle of attack. Opposite effect is obtained sweeping the blade forward. For this reason, purely forward swept shapes are not taken into account in this work.

In the last two decades, several studies, both numerical and experimental, were conducted to show the potential of swept blades. The most complete study on the subject is called Sweep-Twist Adaptive Rotor Blade (STAR) and it was conducted by the Knight \& Craver Wind Group in the SANDIA National Laboratories between 2004 and 2010 [7, 8, 9]. The project started after two feasibility studies: one by Ashwill et al. [10] and the other by Zuteck [11. The STAR constitutes a complete study for swept blades involving aeroelastic simulations, manufacturing, and testing. The project showed that a swept-bladed turbine, with a wider rotor area compared to a straight-bladed baseline, increases the amount of annual energy captured undergoing similar or higher flapwise root bending moments. The implementation of this passive control methods and their potential on multi-mega watt wind turbines was not investigated. Parametric and conceptual studies were carried, but a full overview of the relation between different geometric parameters for the blade planform shape and load alleviations is missing. On a final note, the project cannot provide a "fair" comparison between the swept-bladed turbine and the baseline machine because of the substantial difference in rotor diameter and blade aeroelastic properties.

A detailed parametric study involving geometric parameters for swept blades was conducted by Verelst and Larsen [12. This study is based on several swept blade configurations involving variations on both sweep curvature and sweep offset at the tip. The authors showed that flapwise fatigue and extreme loads can be reduced up to $10 \%$ and $15 \%$, respectively, for a backward swept blade, whereas the edgewise fatigue and extreme loads can increase up to $6 \%$. Verelst and Larsen also mapped the blade root torsional moment, which registered an increase up to $400 \%$. This parametric study is based on a simple load case (10-minute time series with fixed turbulence intensity of 0.18 and no wind shear), and it does not consider a full design load basis (DLB). Consequently, the work can provide only a rough estimation of load variations brought by the employment of swept blades. Instead, a load analysis based on full a DLB would have allowed observations focused on standard requirements for wind turbine design. Furthermore, Verelst and Larsen do not apply any method to compensate the loss in AEP below rated wind speed, and they do not take into account the interaction between the employment of swept blades and the dynamics of the pitch controller. 
Hansen [13] investigated aeroelastic properties of backward swept blades, computing frequencies, damping, and mode shapes of the aeroelastic blade modes. The aeroelastic properties of backward swept blades were deeply investigated, but only a quality estimation of the load alleviations brought by the employment of geometric bend-twist coupling is provided.

Previous studies proved the potential for load alleviation of wind turbines that employ backward swept blades. The focus of the current numerical study is to investigate the design of swept blades through an extensive load analysis based on standard requirements for wind turbines construction and operation. The changes in blade geometry are classified through three parameters: location of the first control point of the Bezier polynomial used to implement the swept shapes, maximum blade tip backward sweep, and blade forward sweep. To ensure a "fair" comparison based on passive-controlled wind turbines with similar AEP and controller dynamics comparable to the baseline, the first part of this study is a pre-processing phase involving aero-servo-elastic modal analysis for controller tuning and aerodynamic twist optimization. Subsequently, a DLB is carried with the purpose of obtaining extreme and fatigue loads used for a realistic wind turbine design. The trends associated to the loading due to the variation of each geometric parameter are analyzed. The general observations provided are applied to the NREL 5 MW RWT 14 to prove the efficacy of the proposed extensive-load-analysis approach.

In the paper, the first section describes the parametric study architecture including details of the geometric parameters used and the workflow that each blade design is subject to. An extensive load analysis and a discussion of the results obtained through the parametric study follows in the next section. The last part of the paper is the application of the outcome of the parametric study on a different blade design, specifically, the blade of the NREL 5 MW RWT.

\section{Parametric Study Architecture}

This section shows the architecture of the parametric study, starting with a description of the different blade geometries considered. A detailed explanation of the models used is provided. At last, a description of the workflow and the DLB used are reported.

\subsection{Swept Blades Shapes and Geometric Parameters}

The blade shapes are obtained using Bezier polynomials [15], which provide the necessary flexibility to obtain the desired backward swept geometries. The control points for the polynomials are placed to avoid curves with very large sweep angles.

Three parameters are selected to describe the shape of the swept blades. Each of these parameters is associated to a letter $(s, b$ or $f)$ and a sequence of numbers having three (in this case, all three digits represent the integer part of the number) or four digits (three digits for the integer part and one for the fractional). The cataloguing system helps the classification of each blade shape, which can be described through a mix of three letters and three numbers representing the combination of the three parameters. The parameters are described as follows: 
- sxxx: location of the first control point on the centerline; it roughly describes the spanwise length where the sweep starts;

- bxxxx: backward sweep at the tip in percentage of the total blade length;

- fxxxx: maximum forward sweep in percentage of the total blade length.

For example, the swept blade classified as s080-b0025-f0005 has a shape where the sweep starts approximately at $80 \%$ of the blade length from the blade root, the backward sweep at the tip is $2.5 \%$, and the maximum forward sweep is $0.5 \%$ of the total blade length.

The parametric study involves a total of 25 blade geometries, divided according to the spanwise location where the first control point for the polynomial is placed. The considered swept shapes are listed as follows:

- Family 1 , the first control point for the Bezier function is placed on the pitch axis at $25 \%$ of the total blade length from the blade root;

- Family 2 , the first control point for the Bezier function is placed on the pitch axis at $50 \%$ of the total blade length from the blade root;

- Family 3, the first control point for the Bezier function is placed on the pitch axis at $80 \%$ of the total blade length from the blade root;

- Family 4 , the first control point for the Bezier function is placed on the pitch axis at $90 \%$ of the total blade length from the blade root;

- Family 5 , the shapes are characterized by a different location of the maximum forward sweep along the blade span.

The only exception is the last family of shapes (Family 5), where the geometries are selected varying the location of the maximum forward swept part. Family 5 is included in the study to investigate whether the location of the maximum forward sweep has an influence on the variation of the blade root torsional moment.

Figure 1 shows a sample of shapes that belongs to the Family 1, where the x-coordinate of the centerline are specified according to the coordinate system defined in the aeroelastic software HAWC2 [16].

\subsection{Numerical Tools and Models Descriptions}

In this work, linear and nonlinear models are implemented. Linear models are used in the pre-processing phase for the tuning of the controller of the swept-bladed wind turbines, and for the aerodynamic twist optimization needed to compensate the loss in AEP (see the next section for detailed explanations). The nonlinear models are used to perform the extensive load analysis that represents the core of the study.

Specifically, linear models are implemented in HAWCStab2 [17] and used for both closedloop aero-servo-elastic eigenvalue analysis and aerodynamic twist optimization. The latter 


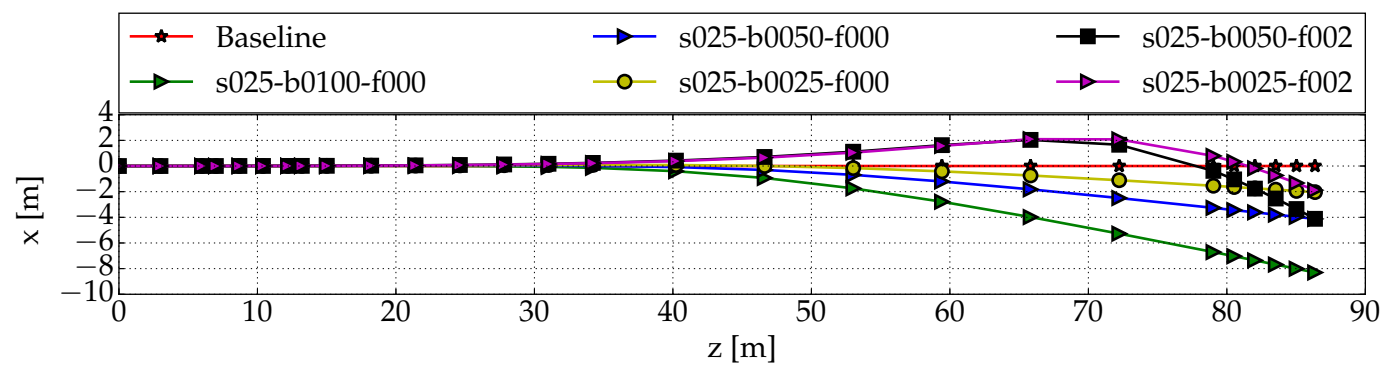

Figure 1: Backward swept shapes of Family 1. $z$ is the coordinate along the blade centerline, whereas $x$ is the coordinate oriented in the edgewise direction. The first control point is located at $25 \%$ span of the total blade length.

is carried out in the multi-disciplinary wind turbine analysis and optimization tool HAWTOpt2 [18, 19, 20, 21]. A detailed description of the HAWCStab2 architecture is provided by Hansen [13], and its validation can be found in [22]. A full description of the HAWTOpt2 framework and its application on aeroelastic optimization of a wind turbine is provided in [23].

The nonlinear models are implemented in the time-domain aero-servo-elastic code HAWC2 [16. The description and the validation of the multi-body formulation used by the structural part of HAWC2 are reported in 24]. The validation of the unsteady BEM method used by the program can be found in [25, 26, 27].

The DTU 10 MW RWT [28] coupled with the Basic DTU Wind Energy Controller [29] are used as the baseline turbine.

\subsection{Workflow and Simulations Set-Up}

Two negative effects are associated with backward swept blades:

- due to the geometric structural coupling, turbines with backward swept blades have a lower AEP compared to a turbine with a straight-bladed rotor because of the decrease in the angle of attack along the blade span during operation [30];

- due to the changes in the structural and aerodynamic response of the blade, i.e. bend-twist coupling effect and change in the angles of attack, respectively, frequencies and damping ratios of the speed regulator mode of turbines with swept blades are significantly different compared to a baseline with straight blades [31].

Each blade design is pre-processed to overcome these two undesired outcomes.

To compensate the loss of AEP below rated wind speed, the aerodynamic twist of each blade design selected is optimized using the HAWTOpt2 framework. The numerical optimization problem is defined as:

$$
\begin{array}{ll}
\max _{\mathbf{x}_{p}(\beta)} & f\left(\mathbf{x}_{p}(\beta), \mathbf{p}\right) \\
\text { s.t. } & \mathbf{g}\left(\mathbf{x}_{p}(\beta)\right) \leq \mathbf{0}
\end{array}
$$


The cost function $f$ depends on a set of variable $\mathbf{x}_{p}(\beta)$ and a set of constant parameters p. For this simple optimization, the design variables are exclusively the parameters that describe the aerodynamic twist of the blade $\beta$. A free form deformation spline (FFD) with 5 control points is used to parametrize the aerodynamic twist as a design variable. The parameters $\mathbf{p}$, including the blade planform, the layups of the blades, and the other components of the wind turbine, are kept constant throughout the optimization. The design variables are normalized, such that when they are equal to zero they correspond to the baseline value.

The cost function, defined in Equation 2, is subject to a set of nonlinear constraints $\mathbf{g}$.

$$
f\left(\mathbf{x}_{p}(\beta), \mathbf{p}\right)=\frac{A E P(\mathbf{0}, \mathbf{p})}{A E P\left(\mathbf{x}_{p}(\beta), \mathbf{p}\right)}
$$

$A E P(\mathbf{0}, \mathbf{p})$ is the annual energy production of the baseline design.

The constraints $\mathrm{g}$ include:

- the rotor thrust, so that the swept-bladed turbines cannot exceed the operational rotor thrust of the baseline;

- the operational lift coefficients that, along the blade span, are limited to avoid stall.

To face the second constraint, after the optimization loop, the controller of the turbines with swept blades is tuned. The tuning of the PI loop of the controller in Region 4 (constant power, torque, and rotational speed) is performed with a pole placement technique. HAWCStab2 is used to perform this tuning adopting a method documented in 32 and 33. The target damping ratio and the target frequency for the pole of the speed regulator mode at $12 \mathrm{~m} \mathrm{~s}^{-1}$ are $70 \%$ and $0.1 \mathrm{~Hz}$, respectively, for all the wind turbines that take part to the parametric study. The frequency of the pole placement for the tuning is changed according to a procedure reported by the authors [31].

A description of the workflow is shown in Figure 2. On the left side of the figure, the tools and a summary of each step of the process are reported. On the right side, a description of the optimization loop explained above is shown.

Simulating the DTU DLB [34] for the design chosen is the last step of the parametric study workflow. The DTU 10 MW RWT was designed based on the IEC 61400-1 load basis [35], disregarding the controller dependent load cases. Therefore, the following modifications are made to the DTU DLB to have a load basis similar to the one used to design the baseline turbine:

- the controller dependent design load case DLC 2.2 is disregarded;

- the extreme values of the loading from DLC 1.1 are not determined using any statistical extrapolation because of the uncertainty related to the choice of an appropriate method; instead, the GL approach [36], which requires a partial safety factor of 1.35, is adopted.

Finally, a load analysis for each wind turbine configuration is carried. Extreme and lifetime equivalent fatigue loads (LTEFL) for the blade root are analyzed, along with AEP 


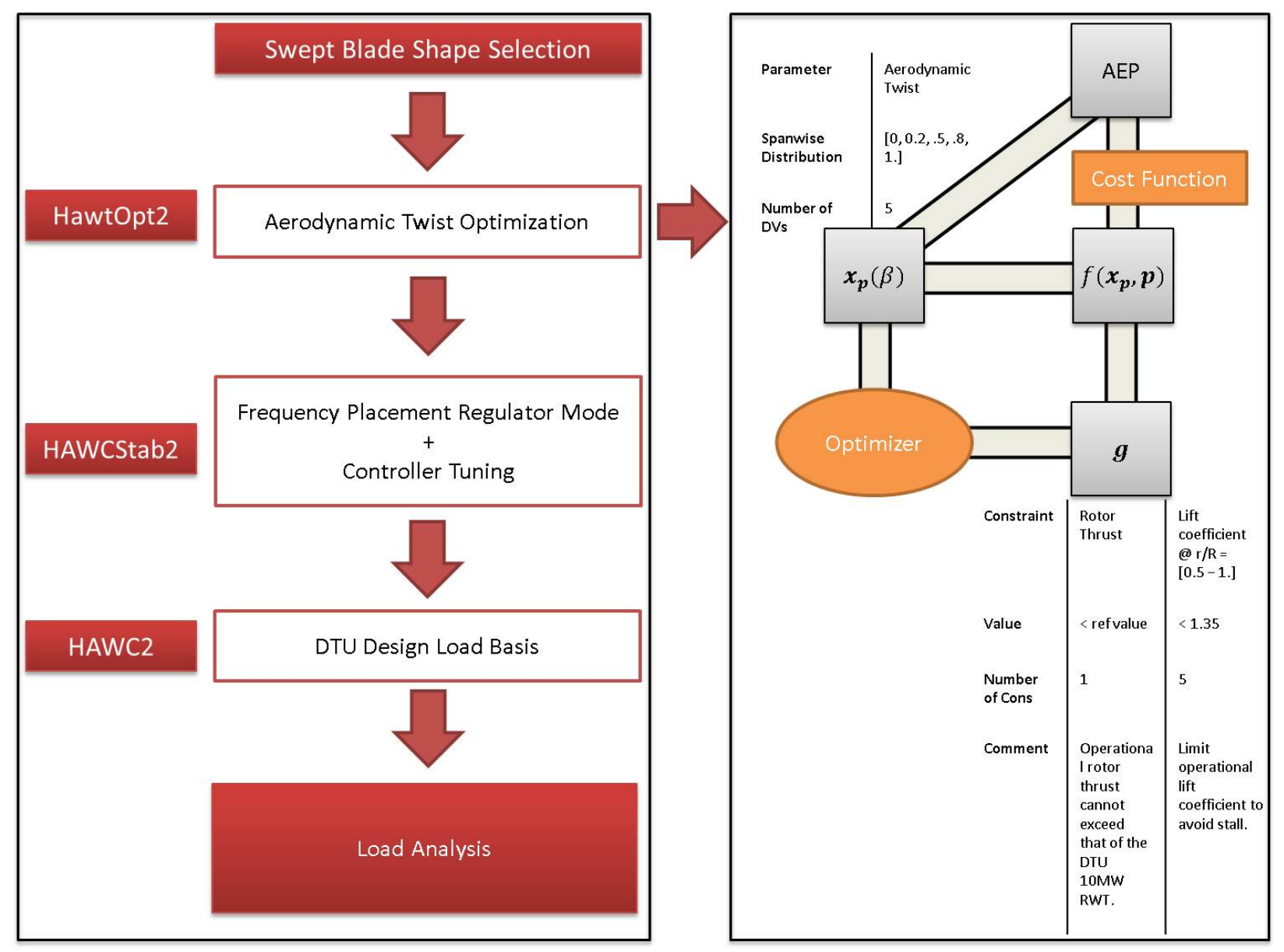

Figure 2: Description of the workflow. The tools and a summary of each step of the workflow are listed on the left side of the figure. On the right side, the optimization loop for the aerodynamic twist is shown.

and tower clearance. The trends associated with the variation of each of the geometric parameters are discussed in the next section, and conclusions on the design of backward swept blades are outlined.

\section{Load Analysis Results}

Numerical results from the load analysis depending on the swept geometries are reported and discussed in this section. In the first part of the section, the blade root extreme and fatigue loads are analyzed, with the purpose of investigating the impact of each geometric parameter of a swept blade. In the second part, AEP and tower clearance are analyzed.

\subsection{Effects of the Location of the First Control Point, Parameter "sxxx"}

The first geometric parameter analyzed is the first control point location along the centerline. This parameter is associated to the location along the blade span where the centerline 
shape starts to change. To examine the impact of this parameter on the extreme loading, the blades with the tip swept backward by $2.5 \%$ of the total blade length, b0025, and with no forward sweep, f0000, are taken into account. Four backward swept blades are considered: s025-b0025-f0000, s050-b0025-f0000, s080-b0025-f0000, and s090-b0025-f0000. The blade centerline of each design chosen is shown in Figure 3 .

Figure 4 shows the normalized absolute maximum blade root bending moment distributions in the blade flapwise (left plot), edgewise (center plot), and torsional (right plot) direction, respectively. The distributions, shown in boxplots, include all the time-series considered in the DLB. To facilitate the comparisons, the loads are non-dimensionalized by the median of the respective baseline distribution. The lower edge of the blue box represents the first quartile, whereas the upper edge is the third quartile. The whiskers delimit the 5th and the 95th percentiles, respectively. Blue crosses are the outliers. The width of the blue box (the interquartile range, IQR), the location of the whiskers (1.8*IQR), and the spread of the outliers give an estimation of the statistical dispersion of the distribution. The uppermost values, highlighted with a green dashed line in Figure 4, are the ultimate loads. The trend of these loads depends on the geometry of the blade selected. However, the ultimate loads are extracted from a single time-series, referring to a single point in the distribution shown in Figure 4. Hence, a comparison between ultimate loads from different designs is deterministic, and it does not take into account the stochastic nature of the turbulent load cases. For example, it is not possible to establish whether the variation on the ultimate loads is caused by the change in blade geometry or the fact that the rotor sees a different turbulence field due to the changed structural and aerodynamic responses or due to tuning of the controller. Therefore in this study, the analysis of the extreme loads is based on the comparison of distributions of the absolute maxima instead of the ultimate loads. Specifically, the extreme load analysis focuses on:

- the medians, which retain information concerning the probability of a certain design having higher or lower absolute maxima across the DLB compared to the baseline;

- the IQR, which provides information on the variability of the absolute maxima across the DLB.

In Figure 4 , the median of the distribution is highlighted in red. The trend of the medians is described by a black dashed line.

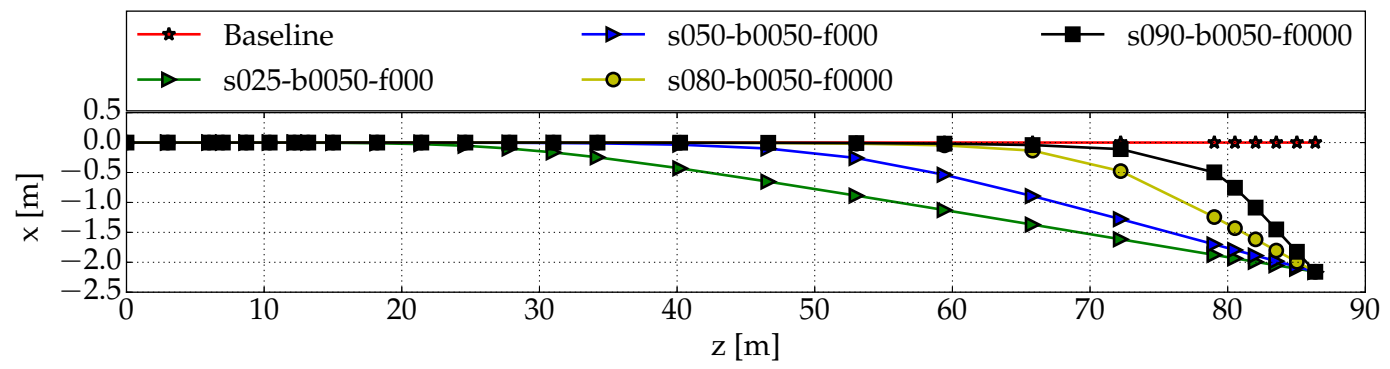

Figure 3: The four backward blade shapes chosen to study the location of the first control point parameter. 

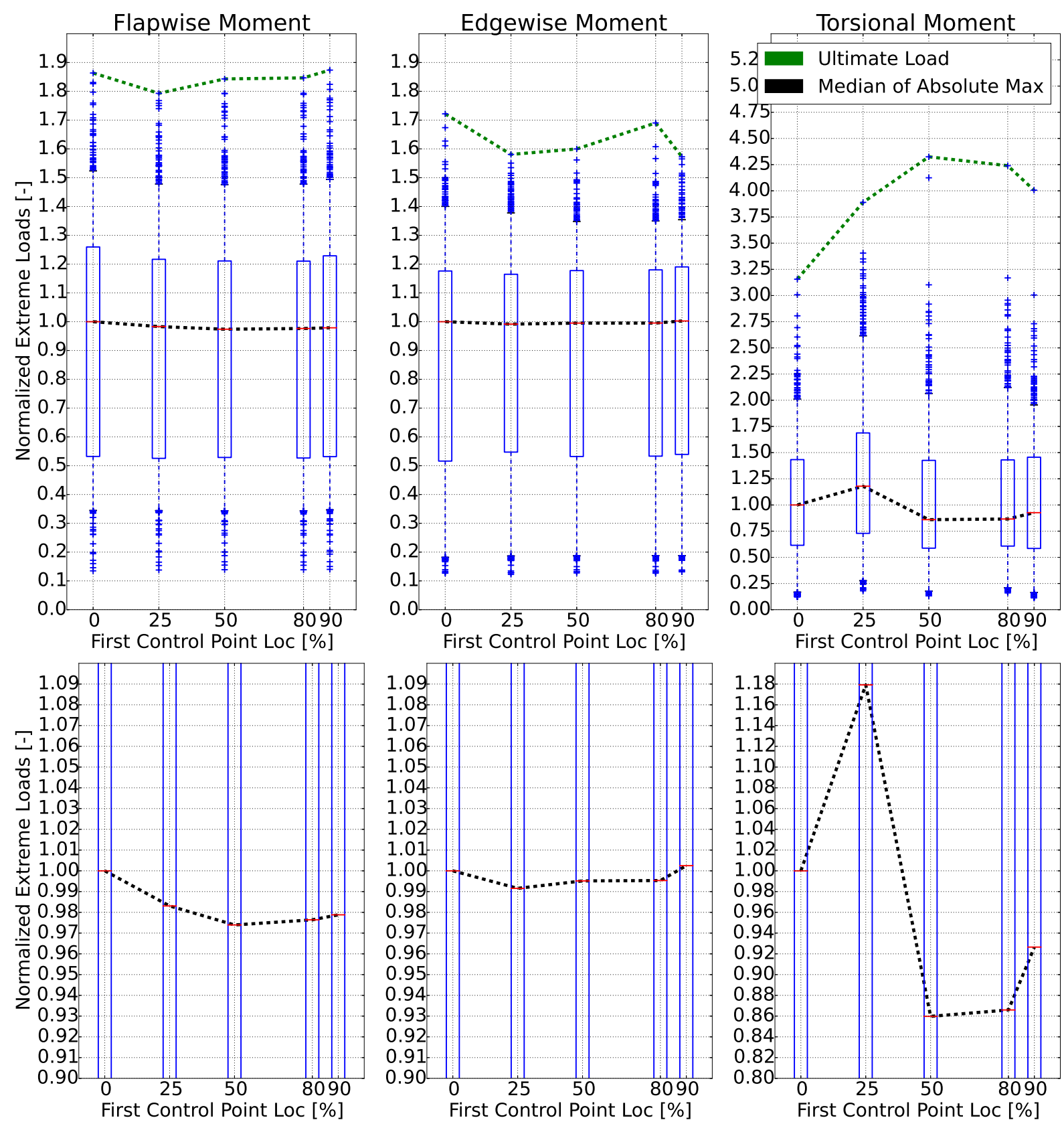

Figure 4: Normalized absolute maxima distributions for baseline and swept blades with ascending first control point location along the blade span. Extreme flapwise, edgewise, and torsional moments are plotted on the left, center, and right, respectively. Bottom plots show a close-up on the medians of the distributions. The loads are non-dimensionalized by the median of the respective baseline distribution.

One can notice the differences between the trend of the ultimate loads and the trend of the medians, especially for the extreme torsional blade root moment. To have a clear view on the medians, the boxes of the absolute maxima distribution are zoomed and reported in the bottom part of Figure 4 . 
The "aggressive" shapes, i.e. with a change in geometry closer to the root (s025-b0025f000 or s050-b0025-f000), have a higher flapwise load alleviation potential because a larger portion of the blade is affected by the change in geometry resulting in the bend-twist coupling. The median and the IQR of the flapwise blade root moments decreases for the s025-b0050-f0000 and s050-b0050-f0000, but it gets closer to the baseline for the shapes that have the first control point close to the blade tip (see Figure4 4, left plot). The decrease in IQR for the absolute maxima of the flapwise moment proves that the backward swept blades are able to reduce the peaks of the extreme blade root flapwise loads.

The median and the IQR of the distributions of the blade root edgewise moment are not significantly changed compared to the baseline (see Figure 4, central plot). Furthermore, the variations of the medians in the edgewise direction are lower in value compared to the variations of the medians in the flapwise direction (compare bottom central and left plots of Figure 44. Therefore, the variation of the first control point location parameter does not affect the blade root edgewise extreme loads.

As already shown in previous studies [9, 12, "aggressive" blade sweeps introduce the largest extreme blade root torsional moments. This effect is clearly shown in the right plot of Figure 44 the medians and the IQRs are getting larger for more "aggressive" swept blades compared to the baseline. The first control point location parameter has a consistent influence on the blade root torsional extreme loads. Different conclusions can be drawn looking at the ultimate torsional loads, where the most "aggressive" shape ( 5050 b0025-f000) has the lowest ultimate torsional load. The latter observation highlights the importance of comparing extreme loads distribution instead of analyzing ultimate loads. To investigate the impact of the parameter "sxxx" on LTEFL, a different set of four backward swept blades, with the blade tip swept backward is fixed at $5.0 \%$, is considered (see Figure 5): s025-b0050-f0000, s050-b0050-f0000, s080-b0050-f0000, and s090-b0050f0000. In this study, the computation of the life time equivalent fatigue loads is based on a life-time of 20 years.

Figure 6 shows the LTEF blade root moments in the flapwise, edgewise, and torsional direction for the considered blade shapes shown in Figure 5. The flapwise LTEFLs (blue circle dashed line) for the all swept blades are lower than the baseline. The edgewise LTEFLs are increased for all the shapes analyzed (red triangle dashed line), as opposed to the flapwise cases. The increases for the edgewise LTEFLs are caused by the increment in

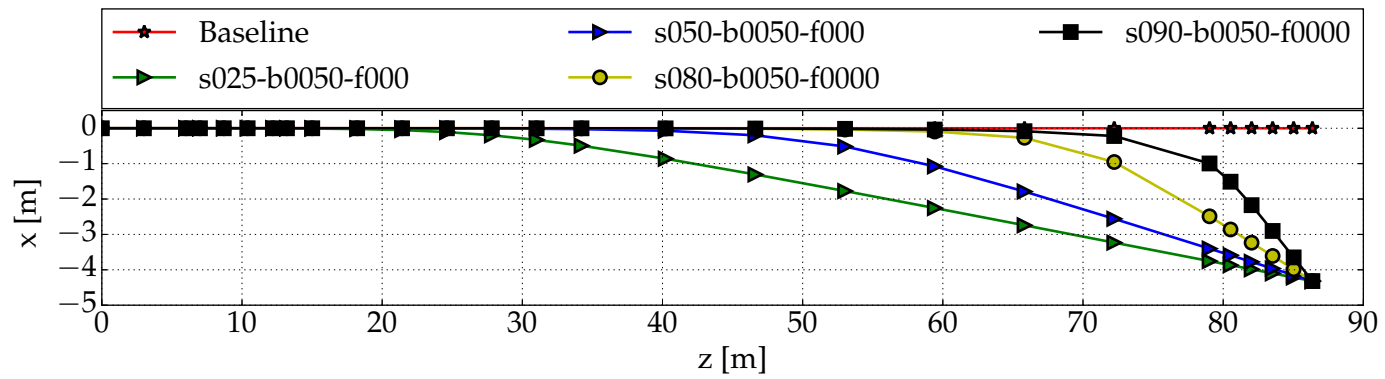

Figure 5: The four backward blade shapes chosen to study the location of the first control point parameter. 


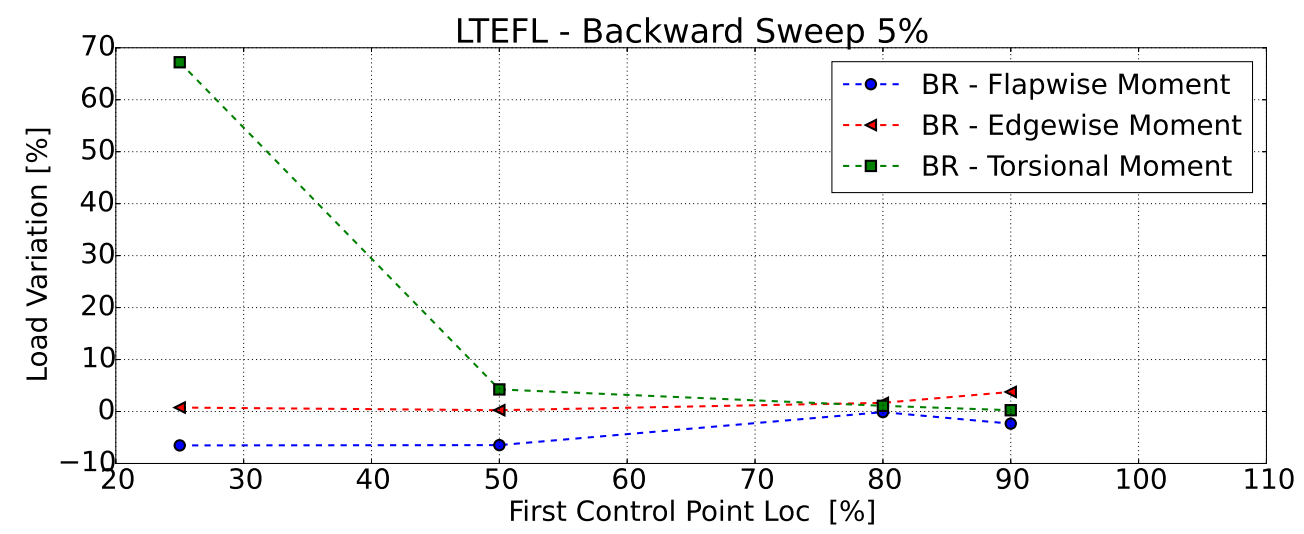

Figure 6: LTEFL blade root moments deviations in percentage from the baseline straight blade (blue circle - flapwise, red triangle - edgewise, green square - torsional). The backward sweep parameter at the tip is fixed at $5 \%$ of the blade length. No forward sweep is considered. Different blade radius along the span are taken into account.

the total mass of the backward swept blades because the swept blades are longer than the baseline. The increase in curvilinear length results in more materials added, producing a design heavier than the baseline blade. An overview of the blade mass increase for all the designs analyzed with respect to the baseline is reported in Table 1. Table 1 shows that the s090-b0050-f0000 has the largest increase in blade mass (1.22\%) between the shapes selected and, consequently, the largest increase in edgewise LTEFL (approximately $3 \%$ ). The trend of the torsional LTEFL (green square dashed line) is similar to the one observed for the medians of the extreme loads distributions in Figure 4, right plot. The highest torsional LTEFL is observed from the most "aggressive" shape, s025-b0050-f0000 blade (approximately 68\% LTEFL increase).

In conclusion, the main problem with the choice of the first control point location parameter to design an effective backward swept blade is the large increase in extreme and fatigue blade root torsional moments. Blade shapes that have a change in geometry that starts closer to the root are longer and heavier than the others and, consequently, present an increase of the edgewise LTEFL.

\subsection{Effects of Maximum Blade Tip Backward Sweep, Parameter "bxxxx"}

The second parameter considered is the maximum blade tip backward sweep, "bxxxx". The other two parameters, "sxxx" and "fxxxx", are fixed to 80 and 0, respectively. Figure 7 shows the considered swept blade geometries, that can be categorized as Family 3.

The absolute maximum load distributions of the considered swept blade geometries are reported in Figure 8 . In the figure, the medians and the IQRs of the flapwise bending moments for the swept blades show a marginal load alleviation effect. The edgewise moment distributions are substantially unchanged, even though it appears that larger sweeps increase the medians due to the total weight increment (see Table 1). Moreover, as shown in Figure 8 on the right plot, increasing the maximum backward sweep at the tip of the blade produces higher medians and IQRs on the absolute maxima distributions of the blade root 
Table 1: Blade total mass variations for the designs analyzed. The baseline blade mass is reported in the second row of the table. The swept blades mass are reported as variation in percentage with respect to the baseline. The identification sequence for the swept blades is reported in the first column.

\begin{tabular}{|l|c|}
\hline Shape & Blade Mass \\
\hline BASELINE & $41716[\mathrm{~kg}]$ \\
\hline s025-b0025-f000 & $0.2[\%]$ \\
\hline s025-b0025-f002 & $0.9[\%]$ \\
\hline s025-b0050-f000 & $0.3[\%]$ \\
\hline s025-b0050-f002 & $1.6[\%]$ \\
\hline s025-b0100-f000 & $1.0[\%]$ \\
\hline s050-b0025-f000 & $0.2[\%]$ \\
\hline s050-b0025-f002 & $1.0[\%]$ \\
\hline s050-b0050-f000 & $0.5[\%]$ \\
\hline s050-b0050-f002 & $2.0[\%]$ \\
\hline s050-b0100-f000 & $1.5[\%]$ \\
\hline s080-b0010-f0005 & $0.3[\%]$ \\
\hline s080-b0025-f0000 & $0.2[\%]$ \\
\hline s080-b0025-f0005 & $0.6[\%]$ \\
\hline s080-b0050-f0000 & $0.5[\%]$ \\
\hline s080-b0100-f0000 & $1.7[\%]$ \\
\hline s090-b0005-f0000 & $0.1[\%]$ \\
\hline s090-b0005-f0002 & $0.2[\%]$ \\
\hline s090-b0010-f0000 & $0.2[\%]$ \\
\hline s090-b0025-f0000 & $0.4[\%]$ \\
\hline s090-b0050-f0000 & $1.2[\%]$ \\
\hline spe1-b0008-f0005 & $0.2[\%]$ \\
\hline spe2-b0010-f0005 & $0.2[\%]$ \\
\hline spe3-b0010-f0005 & $0.2[\%]$ \\
\hline spe4-b0008-f0005 & $0.2[\%]$ \\
\hline spe5-b0005-f0002 & $0.1[\%]$ \\
\hline
\end{tabular}

torsional moment.

Figure 9 shows the blade root LTEFLs. As the blade tip backward sweep increases, 1) the flapwise LTEFLs are reduced due to the higher load alleviation effect brought by larger sweeps, 2) the edgewise LTEFLs are increased due to increment of the total blade weight, and 3) the torsional LTEFLs are increased due to the increasing torque except the s080b0025-f0000. In the latter case, the decrease in blade root torsional fatigue loading, not typical for backward swept blades, can be explained as a consequence of the annual energy production maximization and the change in aerodynamic twist. 


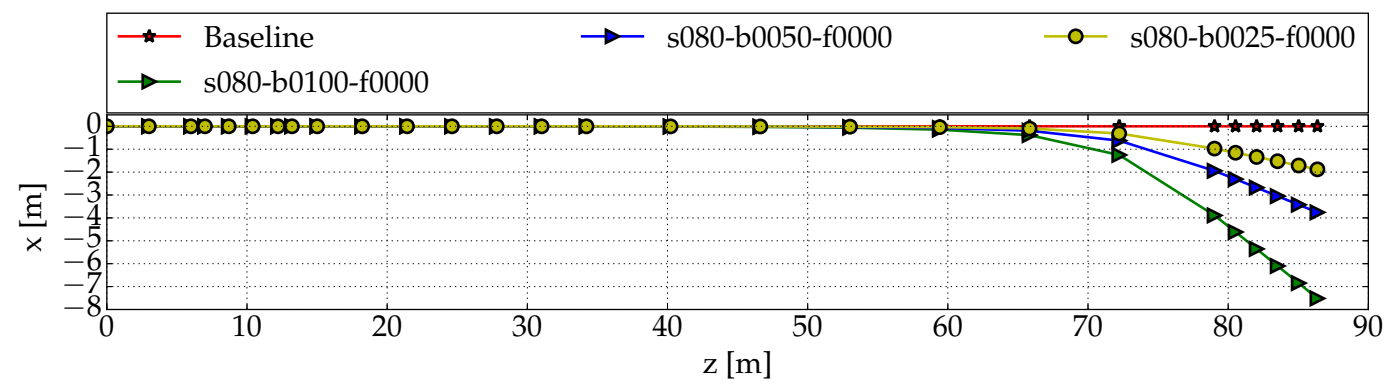

Figure 7: Swept blade shapes of Family 3. First control point for the Bezier polynomial is located on the pitch axis at $80 \%$ of the total blade length.
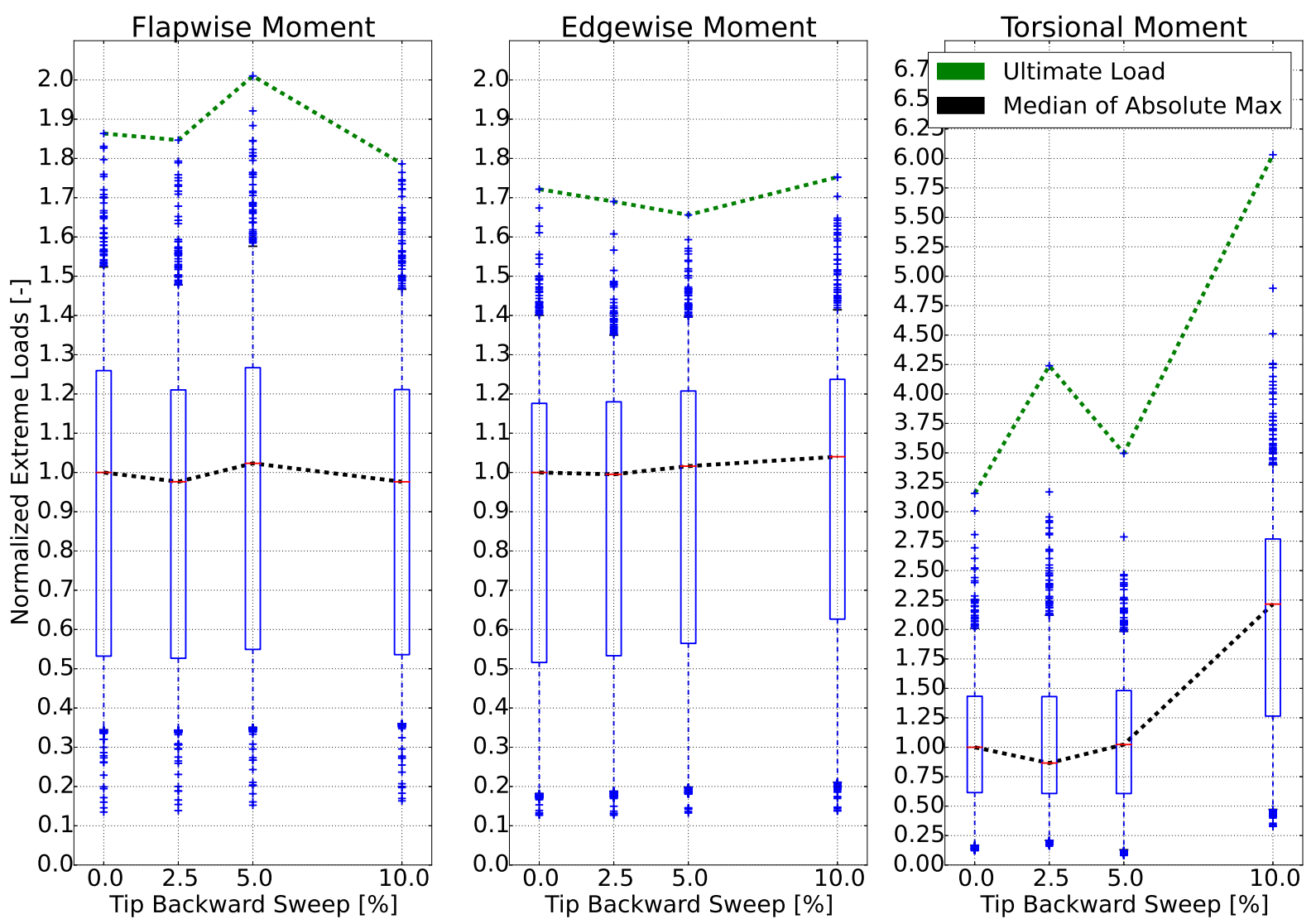

Figure 8: Normalized absolute maxima distributions for baseline and swept blades with increasing maximum backward sweep at the tip. Extreme flapwise, edgewise, and torsional moments are plotted on the left, center, and right, respectively. The loads are non-dimensionalized by the median of the respective baseline distribution.

The variation of the optimized twist along the blade span affects the distribution of the loading. For very mild swept shapes and very large variations of the aerodynamic twist (see the red curve in Figure 10, where the largest variation of the twist is around $5^{\circ}$ ), it is possible to obtain a design that shows alleviations for both flapwise and torsional blade 


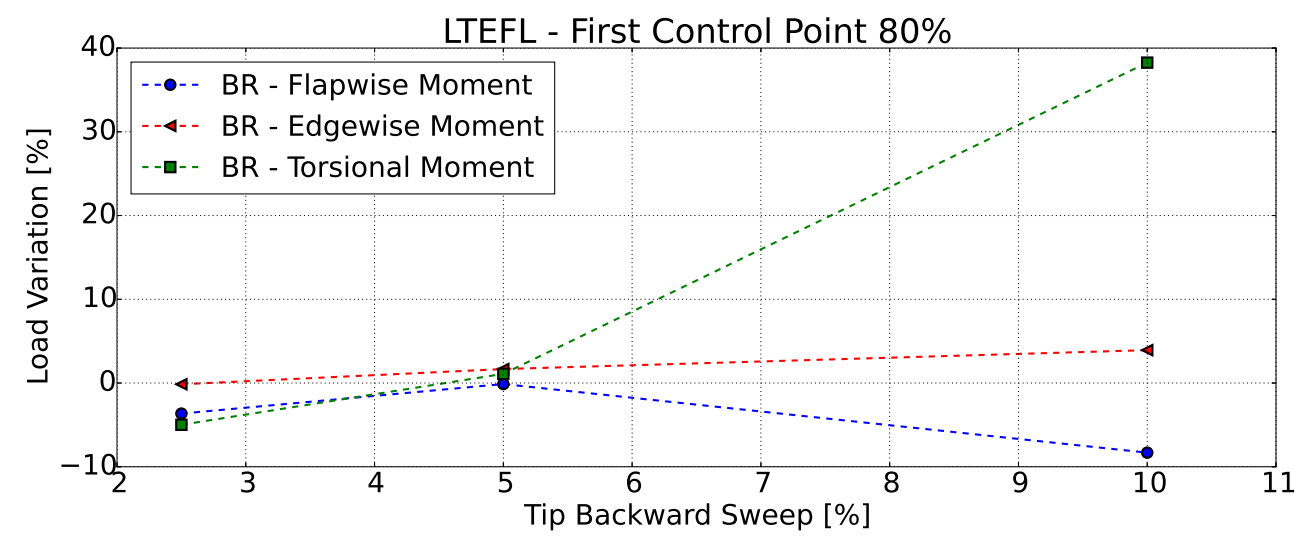

Figure 9: Life Time Equivalent Fatigue Load blade root moments deviations in percentage from the baseline straight blade (blue circle - flapwise, red triangle - edgewise, green square - torsional). All the shapes belong to Family 3. No forward sweep is considered. The variation of the amount of backward sweep at the blade tip is taken into account.

root fatigue loads. This property is difficult to exploit through a parametric study, and it will be the subject of future work. Very large variations of the aerodynamic twist can also have an impact on the flapwise load alleviation potential of some designs. For example, the design s080-b0050-f0000 shows no extreme and LTEF load alleviations compared to the baseline, the s080-b0025-f0000, and the s080-b0100-f0000 (see Figures 8 and 9). The distribution of the flapwise loading is heavily affected by a large variation of the optimized aerodynamic twist, which shows an absolute difference of $7^{\circ}$ at the tip compared to the baseline (see the green curve in Figure 8). The changes in the distribution of the flapwise

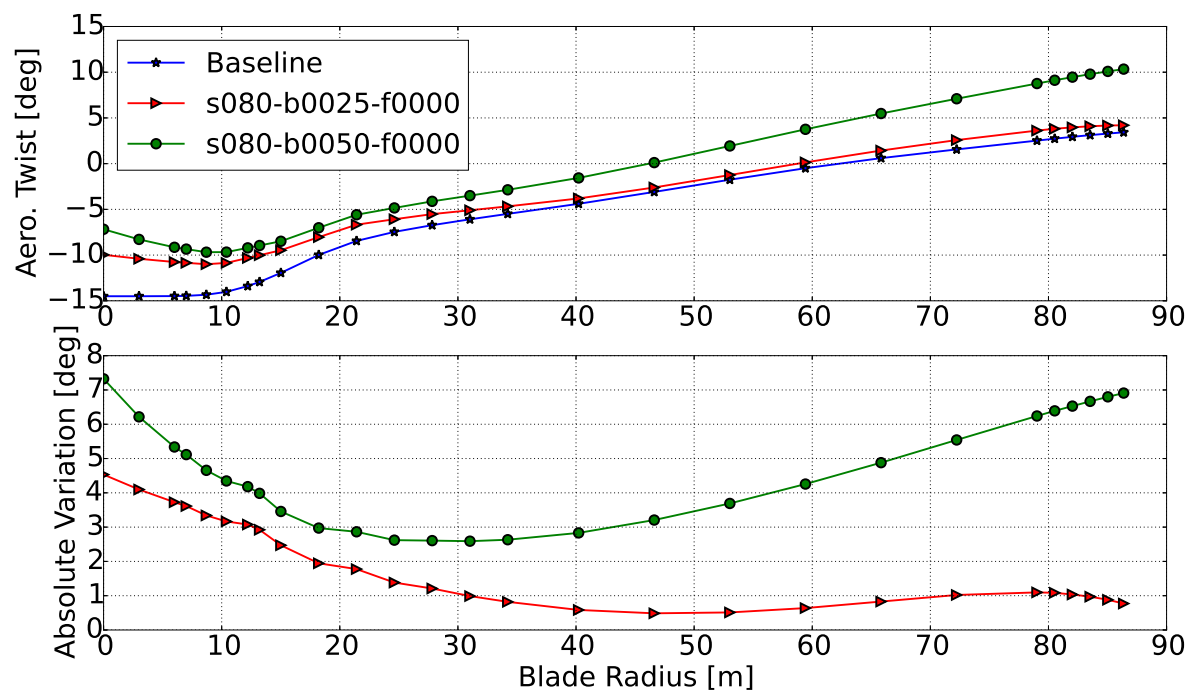

Figure 10: Comparison of the aerodynamic twist of two blades: Baseline (blue star) and s080-b0025-f0000 (red triangle). Top plot shows the aerodynamic twist in degree, while the bottom one shows the absolute value of the variation of the twist of the two swept blades with respect to the baseline blade. 
loading along the blade span have also an effect on the tower clearance. The latter problem is discussed in details in Section 3.4.

Conclusions regarding the analysis of the blade tip backward sweep parameter are similar to the ones reported in the previous section: the parameter has to be chosen considering the minimum increase in torsional extreme and fatigue loading, and taking into account the increase in blade mass due to the increment in blade length brought by the swept shape. Furthermore, it is important to consider that the aerodynamic twist optimization has an impact on the distribution on the aerodynamic loading along the blade span, which can result in a reduction of the blade root torsional moment. Future studies will be carried on the possibility of generating a design that shows alleviations for both flapwise and torsional blade root fatigue loads, as in the case of s080-b0025-f0000. Large variations of the optimized aerodynamic twist can also result in blade designs that show no load alleviation potentials in the flapwise direction.

\subsection{Effects of Blade Forward Sweep, Parameter "fxxxx"}

The last parameter considered is the presence of forward sweep and its location on a swept blade, "fxxxx". For this purpose, two swept blade shape families, Family 1 and Family 5, are used (see Figures 1 and 11). The main reason to implement the forward sweep on a backward swept blade is to reduce the large torsional moment at the root.

Figure 12 shows the extreme blade root moment distributions for the shapes of Family 1 where the forward swept blades (s025-b0025-f002 and s025-b0050-f002) are illustrated with red color.

In general, the inclusion of forward sweep in the backward sweep jeopardizes the load alleviation effect on the extreme flapwise loading (compare medians of the blue and red boxes of the left plot of Figure 12). The reason for this negative outcome lies behind the passive control mechanism used by swept blades. The benefits come from the increase in torsion along the blade length, and the consequent increase in twist towards feather to reduce the angle of attack. The efficacy of this mechanism is reduced if the shape is more "balanced" with a forward sweep. Moreover, the blades with forward sweep are longer and heavier than the respective purely swept shapes, generating an increase in extreme edgewise blade root loading (see medians of the red boxes of the central plot of Figure 12). The torsional

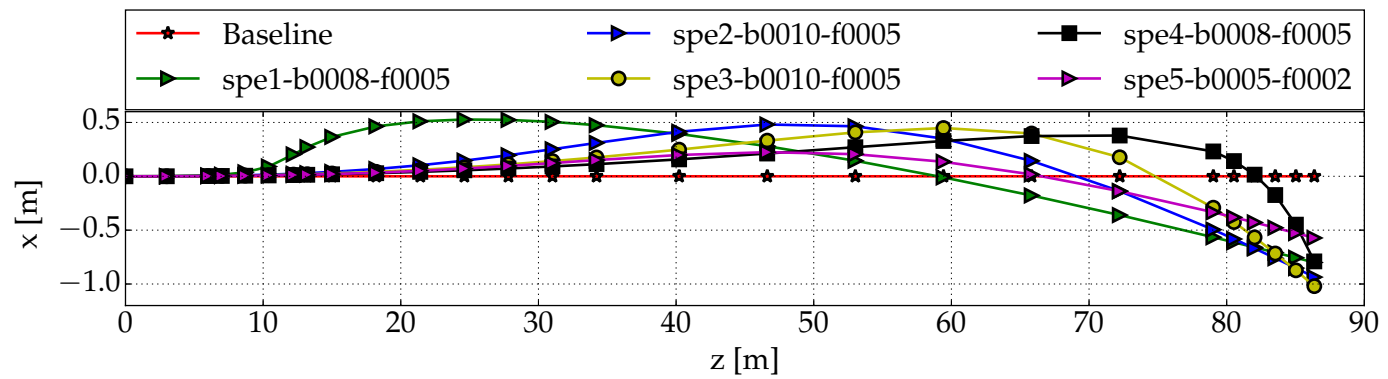

Figure 11: Swept blade shapes of Family 5. Special set of shapes characterized by different locations of the forward swept portion of the blade. 

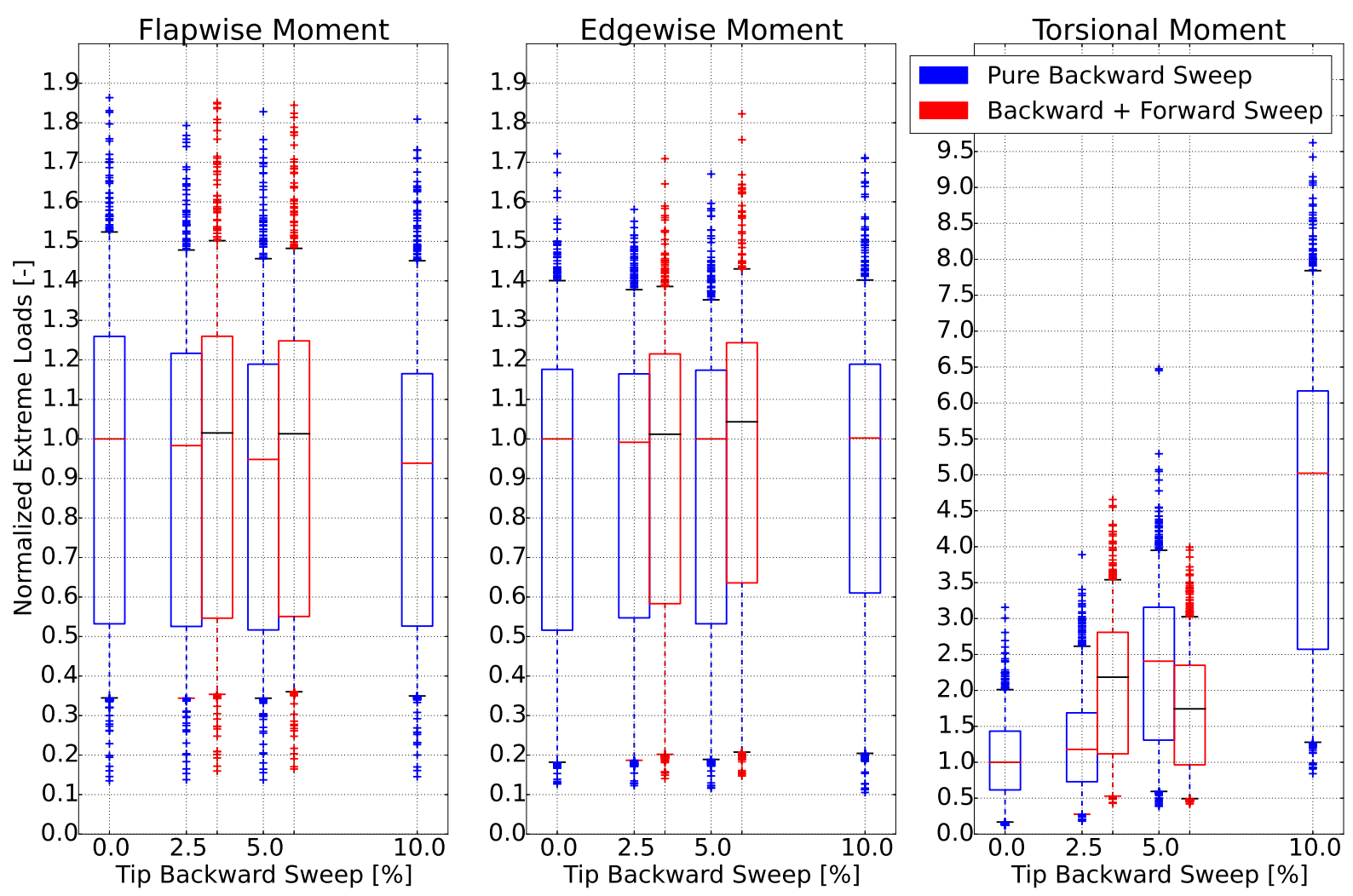

Figure 12: Normalized absolute maxima distributions for baseline and swept blades of Family 1. Extreme flapwise, edgewise, and torsional moments plotted on the left, center, and right, respectively. The loads are non-dimensionalized by the median of the respective baseline distribution. Purely backward swept shapes are denoted using the blue colour. The shapes with forward sweep are highlighted in red.

moments are also affected by the forward sweep. The right plot in Figure 12 shows that the median and the IQRs can be reduced compared to the purely swept back blades ( 5025 b0050-f000 and s025-b0050-f002).

Figures 13 and 14 show the blade root extreme and LTEFLs for the shapes of Family 5, respectively. The analysis of these figures is focused on the understanding of the impact that changing the location of the forward sweep has on the blade root loads.

The blade root flapwise extreme loads and LTEFLs are reduced, even though substantial forward sweep variations are introduced. The amount of LTEFL reductions is lower compared to the alleviations achieved varying the other two geometric parameters, "sxxx" and "bxxxx". The blade edgewise extreme loads and LTEFLs are not significantly affected by the forward sweep because the variation of blade mass for the shapes of Family 5 is very limited, as shown in Table 1. The torsional extreme and LTEFLs are increased for all cases, as shown on one side by the medians of the absolute maxima distributions (see Figure 13, right plot), and on the other side by peaks between approximately 13 and $17 \%$ for the LTEFL (see Figure 14). The amount of the increment is not significant compared to the previous geometric parameters variations analyzed (see Figures 4, 6, 8, and 99). 

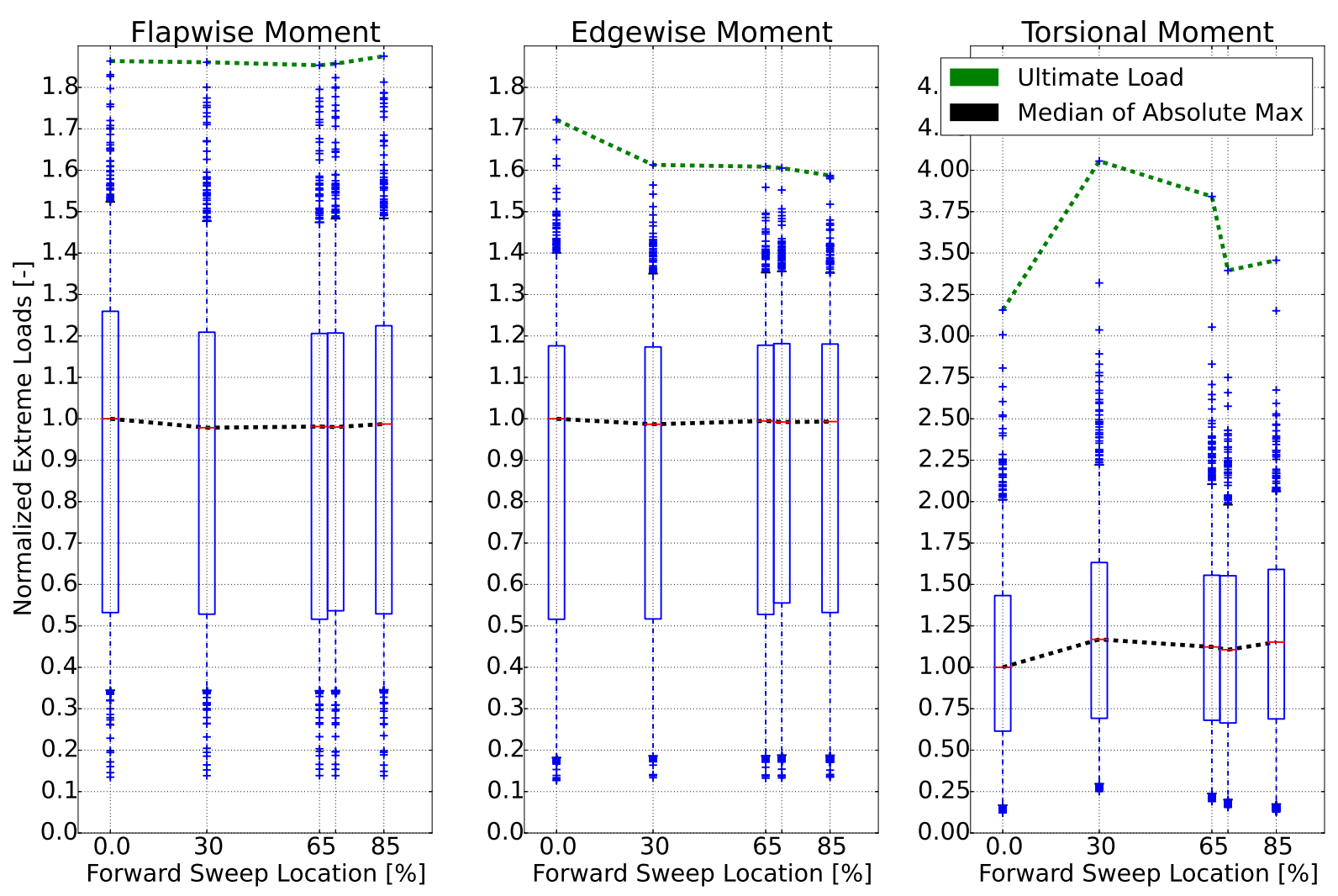

Figure 13: Normalized absolute maxima distributions for baseline and swept blades of Family 5. The loads are non-dimensionalized by the median of the respective baseline distribution.

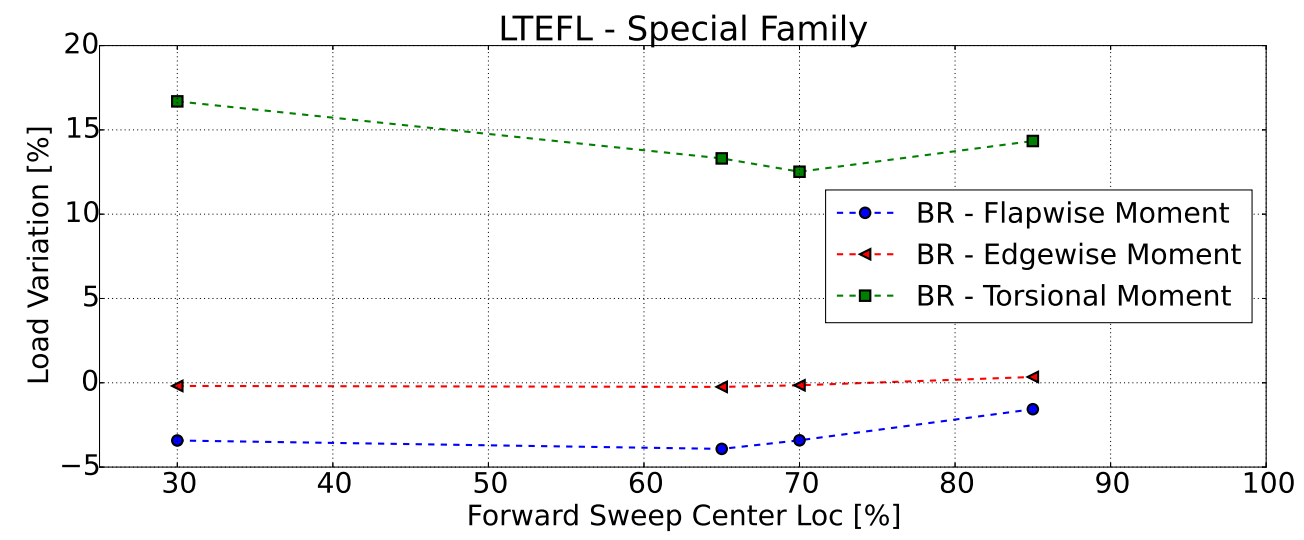

Figure 14: Life Time Equivalent Fatigue Load blade root moments blade root moments deviations in percentage from the baseline straight blade (blue - flapwise, red - edgewise, green - torsional). All the shapes belong to Family 5. Load variations from the baseline are plotted against the location of the forward sweep.

The conclusion is that there is a benefit in introducing forward sweep on backward swept blades. The blade torsional extreme loads and LTEFLs can be less affected by the backward sweep. On the other hand, the load alleviation benefits for the blade flapwise extreme 
loads and LTEFLs are reduced due to the forward sweep.

\subsection{AEP and Tower Clearance}

The annual energy production (AEP) and the tower clearance of all considered swept blades are reported in this section. Table 2 shows the AEP and the tower clearance in percent difference from the baseline values.

The AEP of the backward-swept-bladed turbines are kept very close to the baseline value

Table 2: AEP and tower clearance of the blade designs analyzed. The identification sequence for the swept blades is reported in the first column. The tower clearance results include also the identification sequence for the simulation that showed the minimum tower clearance: "dlc" denotes the Design Load Case, "wsp" the wind speed, "wdir" the wind direction and "s" the turbulence seed realization. The tower clearance takes into account the safety factors assigned by the DLB used.

\begin{tabular}{|l|c|c|c|}
\hline Shape & AEP & \multicolumn{3}{|c|}{ Tower Clearance } \\
\hline BASELINE & $48.497[\mathrm{GW}$ h] & dlc13 wsp12 wdir350 s3005 & $3.656[\mathrm{~m}]$ \\
\hline s025-b0025-f000 & $0.0[\%]$ & dlc13 wsp12 wdir350 s3005 & $4.5[\%]$ \\
\hline s025-b0025-f002 & $0.5[\%]$ & dlc13 wsp12 wdir000 s1005 & $-4.8[\%]$ \\
\hline s025-b0050-f000 & $-0.5[\%]$ & dlc13 wsp12 wdir350 s3005 & $6.0[\%]$ \\
\hline s025-b0050-f002 & $0.8[\%]$ & dlc13 wsp14 wdir000 s2006 & $-7.3[\%]$ \\
\hline s025-b0100-f000 & $0.5[\%]$ & dlc13 wsp12 wdir350 s3005 & $1.3[\%]$ \\
\hline s050-b0025-f000 & $-0.2[\%]$ & dlc13 wsp12 wdir350 s3005 & $1.5[\%]$ \\
\hline s050-b0025-f002 & $0.7[\%]$ & dlc13 wsp12 wdir350 s3005 & $-1.0[\%]$ \\
\hline s050-b0050-f000 & $0.1[\%]$ & dlc13 wsp12 wdir350 s3005 & $-4.6[\%]$ \\
\hline s050-b0050-f002 & $1.0[\%]$ & dlc13 wsp14 wdir000 s2006 & $-4.1[\%]$ \\
\hline s050-b0100-f000 & $0.7[\%]$ & dlc13 wsp12 wdir350 s3005 & $-1.6[\%]$ \\
\hline s080-b0010-f0005 & $0.8[\%]$ & dlc13 wsp12 wdir010 s6005 & $-9.3[\%]$ \\
\hline s080-b0025-f0000 & $-0.2[\%]$ & dlc13 wsp12 wdir350 s3005 & $1.8[\%]$ \\
\hline s080-b0025-f0005 & $0.5[\%]$ & dlc13 wsp12 wdir350 s3005 & $0.1[\%]$ \\
\hline s080-b0050-f0000 & $0.9[\%]$ & dlc13 wsp12 wdir350 s3005 & $-10.1[\%]$ \\
\hline s080-b0100-f0000 & $0.8[\%]$ & dlc13 wsp12 wdir350 s3005 & $-5.8[\%]$ \\
\hline s090-b0005-f0000 & $-0.3[\%]$ & dlc13 wsp12 wdir350 s3005 & $-3.3[\%]$ \\
\hline s090-b0005-f0002 & $-0.3[\%]$ & dlc13 wsp12 wdir350 s3005 & $-3.9[\%]$ \\
\hline s090-b0010-f0000 & $-0.3[\%]$ & dlc13 wsp12 wdir350 s3005 & $-2.2[\%]$ \\
\hline s090-b0025-f0000 & $0.0[\%]$ & dlc13 wsp12 wdir350 s3005 & $-2.7[\%]$ \\
\hline s090-b0050-f0000 & $0.8[\%]$ & dlc13 wsp12 wdir350 s3005 & $-3.1[\%]$ \\
\hline spe1-b0008-f0005 & $-0.3[\%]$ & dlc13 wsp12 wdir350 s3005 & $4.1[\%]$ \\
\hline spe2-b0010-f0005 & $-0.3[\%]$ & dlc13 wsp12 wdir350 s3005 & $4.5[\%]$ \\
\hline spe3-b0010-f0005 & $-0.2[\%]$ & dlc13 wsp12 wdir350 s3005 & $3.0[\%]$ \\
\hline spe4-b0008-f0005 & $-0.2[\%]$ & dlc13 wsp12 wdir350 s3005 & $3.3[\%]$ \\
\hline spe5-b0005-f0002 & $-0.4[\%]$ & dlc13 wsp12 wdir350 s3005 & $2.7[\%]$ \\
\hline
\end{tabular}


due to the aerodynamic twist optimization scheme implemented at the pre-processing phase (see Figure 2). The variations of AEP are always below 1\%, and the drops for the turbines with worse performances are never greater than $0.5 \%$.

The tower clearance is calculated as the distance between the blade tip and the closest outer section of the tower. The measured tower clearance window is between $175^{\circ}$ and $185^{\circ}$ azimuth, for a blade pointing upward at $0^{\circ}$ azimuth. All the swept blade designs analyzed satisfy the requirement for tower clearance demanded by the IEC standard [35]. The load alleviation effect brought by the sweep reduces the flapwise displacement of the tip. Consequently, a higher tower clearance is expected from all the turbines that takes part to the parametric study, but some of the designs show a substantial decrease of the minimum tower clearance. The reason lies behind the optimization process where the optimizer might need to significantly increase the aerodynamic twist at the blade tip to maximize the AEP, causing an increase in the angle of attack around rated wind speed. The change in angle of attack introduces higher loads at rated wind speed where the minimum tower clearance is registered. Figure 15 shows the aerodynamic twist distributions for two different swept blade cases and their comparison with the baseline design. On one hand, the s080-b0050-f0000 blade (plotted in circle with green color) has a significant increase of the aerodynamic twist at the blade tip (approximately $7^{\circ}$ at the blade tip, as shown in the bottom plot of Figure 15) which results in a decrease of the tower clearance of approximately 10\%. On the other hand, the s025-b0050-f000 blade design (plotted in triangle with red color) shows an increase of tower clearance of approximately $6 \%$ whereas the aerodynamic twist at the tip of the blade is not significantly increased (approximately $1^{\circ}$ at the blade tip shown in the bottom plot of Figure 15 .

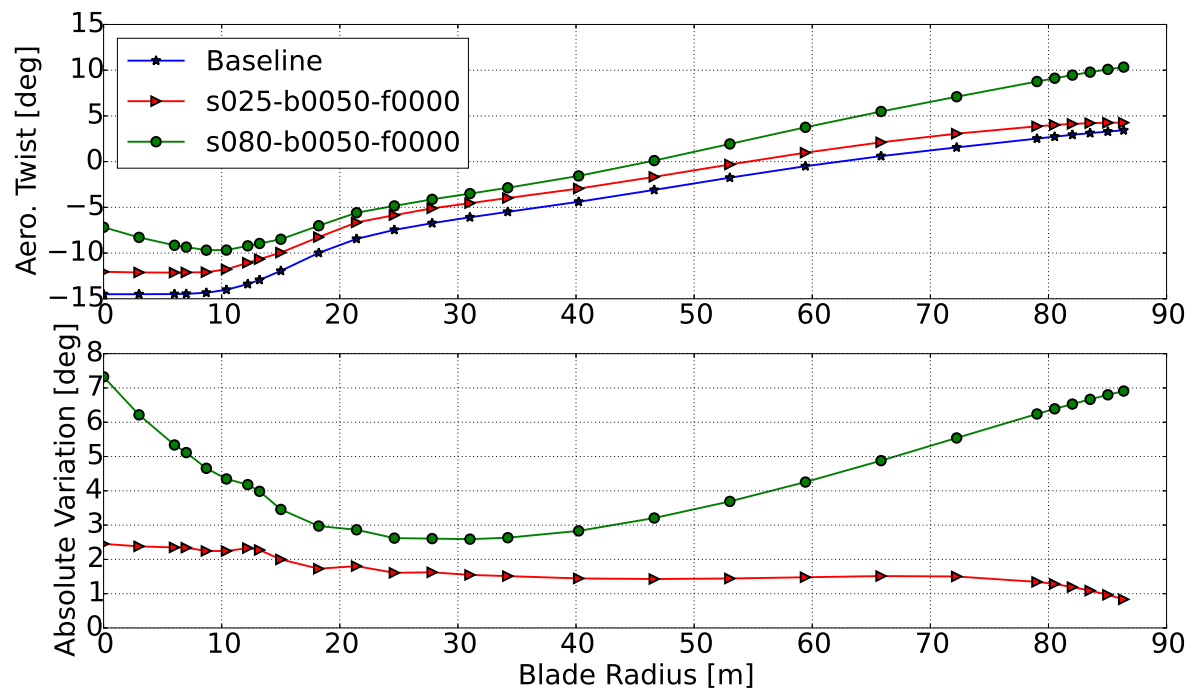

Figure 15: Comparison of the aerodynamic twist of three blades: Baseline (blue star), s025-b0050-f000 (red triangle), and s80-b0050-f0000 (green circle). Top plot shows the aerodynamic twist in degree, while the bottom one shows the absolute value of the variation of the twist of the two swept blades with respect to the baseline blade. 
To keep or increase the tower clearance, the aerodynamic twist should be constrained during the optimization. An alternative is to pitch the blade towards stall below rated wind speed, to compensate for the reduction in the angle of attack generated by the sweep [30]. The latter solution has the advantage of being less computationally expensive than the optimization routine. Particular attention must be paid to avoid stall along the blade span below rated wind speed.

\section{Swept Blade Design Application: the NREL 5MW RWT}

In this section, one of the obtained swept blade designs from the DTU 10 MW RWT is applied to a different class turbine blade to verify its performances. In this study, the NREL 5 MW RWT is used [14] with the Basic DTU Wind Energy Controller [29]. The s080-b0025-f0000 backward swept blade is selected for this study based on the investigations made in the previous sections:

- avoid forward sweep in any part of the blade because it reduces (or completely eliminate) the load alleviation effect;

- let the backward sweep start closer to the blade tip $(80 \%$ or $90 \%$ of the total blade length) to avoid an excessive increase in blade root torsional moment;

- contain the maximum backward sweep at the tip within $5 \%$ of the total blade length to avoid a very large blade root torsional moment;

- optimize the aerodynamic twist or pitch the blade towards stall below rated wind speed to compensate the loss in AEP due to the decrease in the angle of attack; be aware of the risks of the two strategies: the optimization of the aerodynamic twist to maximize the AEP can increase the loading at the blade tip around rated wind speed reducing the tower clearance; pitching the blade towards stall below rated wind speed can drive part of the blade into stall.

The considered blade is pitched towards stall below rated wind speed to compensate the loss in AEP compared to the baseline design. This approach is preferred to the aerodynamic twist optimization because it does not have the negative impact on the tower clearance described earlier, and it is computationally cheap.

The same design load cases based on 34 with the modifications reported in Section 2.3 are considered.

\subsection{AEP and Tower Clearance}

Table 3 shows the comparison of AEP and tower clearance between the baseline wind turbine and the swept-bladed one. The passive-controlled wind turbine has approximately the same annual energy production of the baseline, registering a very small loss of $0.04 \%$. An increase in tower clearance can be observed (3.5\%). 
Table 3: AEP and tower clearance of the NREL 5 MW RWT with straight and backward swept blades (s080-b0025-f0000). The AEP and tower clearance for the baseline blade are reported in the second row of the table. The tower clearance results include also the identification sequence for the simulation that showed the minimum tower clearance: "dlc" denotes the Design Load Case, "wsp" the wind speed, "wdir" the wind direction and "s" the turbulence seed realization. The tower clearance takes into account the safety factors assigned by the DLB used.

\begin{tabular}{|l|c|l|l|}
\hline Blade Design & AEP & \multicolumn{3}{|c|}{ Tower Clearance } \\
\hline NREL 5MW RWT & $24.197[\mathrm{GW} \mathrm{h}]$ & dlc13 wsp12 wdir010 s5005 & $1.767[\mathrm{~m}]$ \\
\hline s080-b0025-f0000 & $-0.04[\%]$ & dlc13 wsp12 wdir010 s5005 & $+3.5[\%]$ \\
\hline
\end{tabular}

Table 4: Blade mass of the NREL 5 MW RWT with straight and backward swept blades (s080-b0025f0000). The mass of the swept blade loads is reported as variation in percentage from the baseline.

\begin{tabular}{|l|c|}
\hline Blade Design & Blade Mass \\
\hline NREL 5MW RWT & $17740[\mathrm{~kg}]$ \\
\hline s080-b0025-f0000 & $+0.19[\%]$ \\
\hline
\end{tabular}



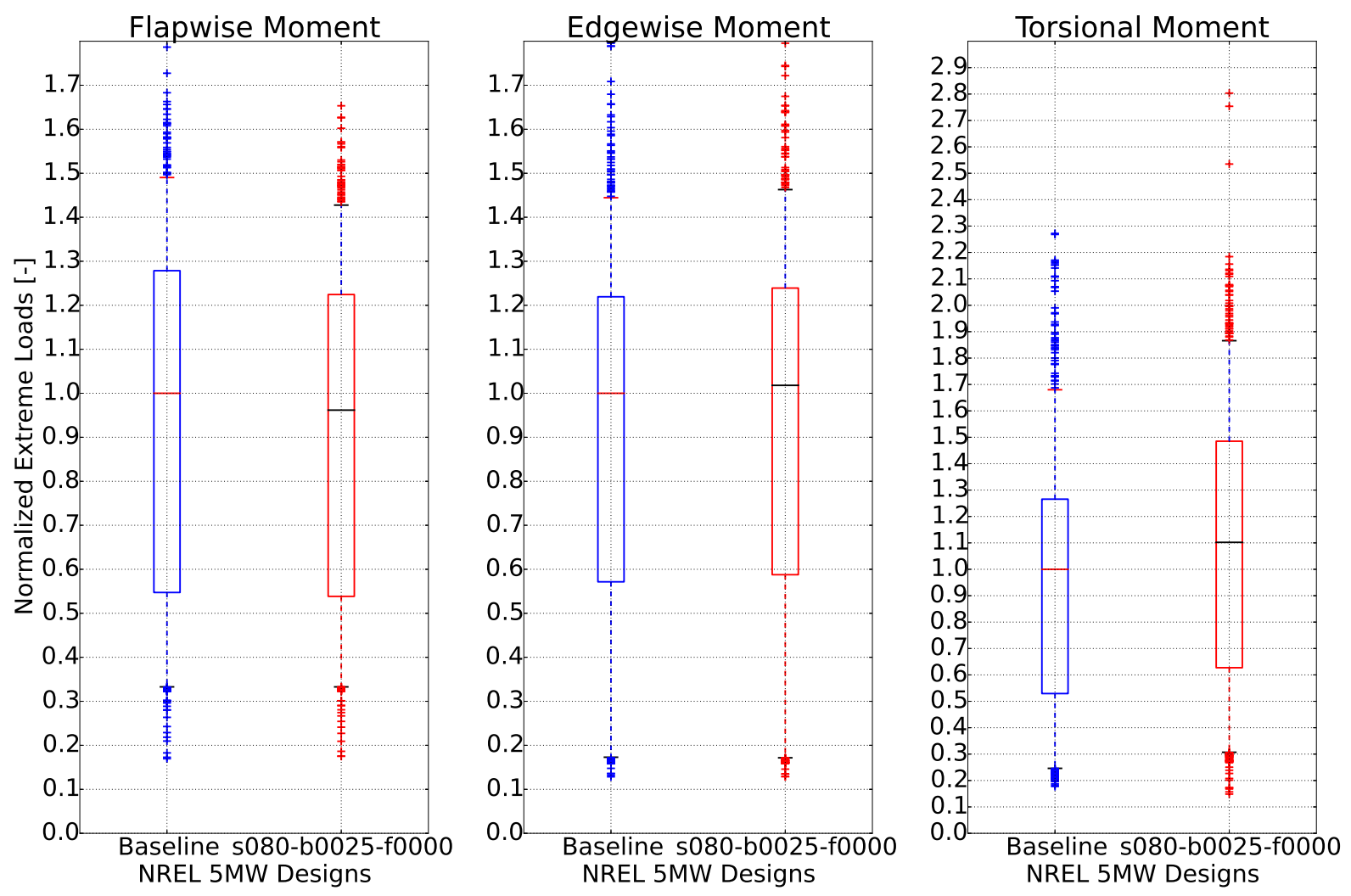

Figure 16: Normalized absolute maxima distributions for baseline and swept blade of the NREL 5MW. The loads are non-dimensionalized by the median of the respective baseline distribution.

Table 5: LTEFL blade root moments of the NREL 5 MW RWT with straight and backward swept blades (s080-b0025-f0000). In the three rightmost columns, the blade root flapwise moment, the blade root edgewise moment, and the blade root torsional moment are respectively reported. The fatigue loads for the baseline blade are reported in absolute values in the second row of the table. The fatigue loads for the swept blade are reported as variation in percentage from the baseline.

\begin{tabular}{|l|c|c|c|}
\hline Blade Design & LTEFL BR Flap & LTEFL BR Edge & LTEFL BR Tors. \\
\hline NREL 5MW RWT & $10092.379[\mathrm{kN} \mathrm{m}]$ & $7218.318[\mathrm{kN} \mathrm{m}]$ & $184.232[\mathrm{kN} \mathrm{m}]$ \\
\hline s080-b0025-f0000 & $-6.3[\%]$ & $+0.2[\%]$ & $-2.8[\%]$ \\
\hline
\end{tabular}


From the investigation with the NREL 5 MW RWT, it can be concluded that the outcomes of the extensive load analysis of the DTU 10 MW RWT can be applied to other wind turbines, ensuring the creation of a swept blade design able to provide beneficial passive load alleviations.

\section{Conclusions}

This paper studies extensive load analyses to investigate the backward swept blade designs for passive load alleviation on multi-megawatt wind turbines. To introduce various swept geometries, three representative parameters are considered:

- position along the blade span where the sweep starts;

- maximum backward sweep at the blade tip;

- maximum forward sweep.

Based on these three parameters, 25 shapes divided in 5 families were selected. The blade of the DTU 10 MW RWT was used as baseline. In general, the backward swept blades produce less electrical energy compared to the straight blade. Therefore, all the considered swept blades were pre-processed to provide the same amount of the annual energy production (AEP). An optimization approach was introduced. The aerodynamic twist was updated for each swept blade design to maximize the annual energy production, compensating the AEP loss below rated wind speed. After that, the tuning of the controller according to a specific frequency placement of the regulator mode was performed as well. A full design load basis was adapted and analyzed for each of the swept designs selected.

The variation of each geometric parameter was analyzed separately producing the following observations:

- "sxxx": the choice of the first control point location parameter is driven by the large increase in extreme and fatigue blade root torsional moment, and the increase of the edgewise LTEFL due to the increase in blade length more pronounced as the sweep starts closer to the root;

- "bxxxx": the parameter has to be chosen considering the minimum increase in torsional extreme and fatigue loading, and taking into account the increase in blade mass due to the increment in blade length brought by the swept shape;

- "fxxxx": the presence of forward sweep helps compensating excessive increments of the torsional moment, but it also reduces or cancels the beneficial effects due to the sweep; moreover, the location of the forward sweep along the blade span does not have a relevant influence on the loading.

To summarize, mildly and purely backward swept shapes are the best option for the design of passive-controlled wind turbines because they can achieve load alleviations without causing large increases in blade root torsional moment. 
Annual energy production and tower clearance were monitored as well. The optimization of the aerodynamic twist to maximize AEP produces negative effects on the tower clearance of some of the designs analyzed. The optimizer increases the aerodynamic twist at the blade tip to fulfil the loss in AEP below rated wind speed, resulting in higher angles of attack and higher loads at the tip around rated wind speed compared to the baseline design. This process causes a reduction of the tower clearance with respect to the RWT and a different distribution of the loading along the blade span.

The observations obtained through the load analysis of all the DTU 10 MW RWT were applied to a different wind turbine, specifically, the NREL 5 MW RWT. From this study similar trends between the DTU 10 MW RWT and the NREL 5 MW RWT were observed. The outcome of the parametric study can be generally applied to produce a passive-controlled wind turbine with reduced flapwise extreme and fatigue loads, and inevitable increase in extreme and fatigue blade root torsional moment.

\section{Acknowledgements}

The present work is funded by the European Union's Seventh Program for research, technological development and demonstration under grant agreement No.308974 through the project INNWIND (Innovative Wind Conversion Systems (10-20MW) for Offshore Applications) and by the International Collaborative Energy Technology R\&D Program of the Korea Institute of Energy Technology Evaluation and Planning (KETEP), granted financial resources by the Ministry of Trade, Industry \& Energy, Republic of Korea. (No. 20138520021140). The programs are gratefully acknowledged.

\section{References}

[1] M. Taylor, K. Daniel, A. Ilas, E. Y. So, Renewable Power Generation Costs in 2014, IRENA - International Renewable Energy Agency, Bonn, Germany, 2015.

[2] S. Krohn, P. E. Morthorst, S. Awerbuch, The Economics of Wind Energy: A report by the European Wind Energy Association, EWEA - The European Wind Energy Association, March 2009.

[3] T. D. Ashwill, Materials and Innovations for Large Blade Structures: Research Opportunities in Wind Energy Technology, in: 50th AIAA Structures, Structural Dynamics, and Materials Conference, pp. AIAA-2009-2407. Palm Springs, USA, May, 2009.

[4] E. A. Bossanyi, Individual Blade Pitch Control for Load Reduction, Journal of Wind Energy (2003) 119-128. Doi: 10.1002/we.76.

[5] T. K. Barlas, L. Bergami, M. H. Hansen, M. M. Pedersen, D. Verelst, K. Thomsen, H. A. Madsen, Load alleviation potential of the Controllable Rubber Trailing Edge Flap (CRTEF) in the INDUFLAP project, DTU Wind Energy, DTU Vindenergi-E0065(EN), Roskilde, December 2014. 
[6] H. Kooijman, Bending-torsion coupling of a wind turbine rotor blade, ECN report I-96-060, Petten, December 1996.

[7] S. Larwood, M. Zuteck, Swept Wind Turbine Blade Aeroelastic Modeling for loads and dynamic behavior, in: Windpower 2006, p. 17. Pittsburgh, USA, 4-7 June 2006.

[8] T. D. Ashwill, G. Kanaby, K. Jackson, M. Zuteck, Development of the swept twist adaptive rotor (STAR) blade, in: Proceedings of the 48th AIAA Aerospace Sciences Meeting. Orlando, Florida, 4-7 January 2010.

[9] Knight and Carver Wind Group, Sweep-Twist Adaptive Rotor Blade: Final Project Report, Sandia National Laboratories, SAND2009-8037, Albuquerque, New Mexico, USA, 2010.

[10] T. Ashwill, P. S. Veers, J. Locke, I. C. D. Griffin, M. D. Zuteck, Concepts for Adaptive Wind Turbine Blades, in: ASME 2002 Wind Energy Symposium, Paper No. WIND2002-28, pp. 56-69. Reno, Nevada, USA, 14-17 January 2002, doi:10.1115/WIND2002-28.

[11] M. Zuteck, Adaptive Blade Concept Assessment: Curved Planform Induced Twist Investigation, Sandia National Laboratories, SAND2002-2996, Albuquerque, New Mexico, USA, 2002.

[12] D. R. S. Verelst, T. J. Larsen, Load consequences when sweeping blades - a case study of a 5 MW pitch controlled wind turbine, Ris $\varnothing-\mathrm{DTU}$, Technical Report Ris $\varnothing-\mathrm{R}-1724$, Roskilde, May 2010.

[13] M. H. Hansen, Aeroelastic properties of backward swept blades, in: Proceedings of the 49th AIAA Aerospace Sciences Meeting. Orlando, Florida, USA, 4-7 January 2011.

[14] J. Jonkman, S. Butterfield, W. Musial, G. Scott, Definition of a 5-MW Reference Wind Turbine for Offshore System Development, National Renewable Energy Laboratories, Technical Report, NREL/TP-500-38060, Golden, Colorado, USA, February 2009.

[15] A. Quarteroni, R. Sacco, F. Saleri, Numerical Mathematics, Springer-Verlag New York, Inc., 2000, ISBN 0-387-98959-5.

[16] T. J. Larsen, A. M. Hansen, How 2 HAWC2, the user's manual, DTU Wind Energy, Ris $\varnothing-R-1597(v e r .4 .6)(E N)$, Roskilde, Denmark, 2015.

[17] L. C. Henriksen, C. Tibaldi, L. Bergami, HAWCStab2 User Manual, DTU Wind Energy, Technical Report, Roskilde, Denmark, 2015.

[18] NASA, http://openmdao.org, 2012. 
[19] K. T. Moore, B. A. Naylor, J. S. Gray, The Development of an Open-Source Framework for Multidisciplinary Analysis and Optimization, in: 10th AIAA/ISSMO Multidisciplinary Analysis and Optimization Conference. AIAA 2008-6069, Victoria, Canada, August 2008.

[20] J. S. Gray, K. T. Moore, B. A. Naylor, OPENMDAO: An Open Source Framework for Multidisciplinary Analysis and Optimization, in: 13th AIAA/ISSMO Multidisciplinary Analysis and Optimization Conference. AIAA-2010-9101, Fort Worth, Texas, USA, August 2010, http://www.aric.or.kr/treatise/journal/content.asp?idx=134451.

[21] C. M. Heath, J. S. Gray, OpenMDAO: Framework for Flexible Multidisciplinary Design, Analysis and Optimization Methods, in: 8th AIAA Multidisciplinary Design Optimization Specialist Conference (MDO), pp. 1-13. Honolulu, Hawaii, USA, 2012.

[22] I. Sønderby, M. H. Hansen, Open-loop frequency response analysis of a wind turbine using high-order linear aeroelastic model, Journal of Wind Energy (2013). Doi: $10.1002 /$ we.1624.

[23] F. Zahle, C. Tibaldi, D. R. Verelst, C. Bak, R. Bitche, J. P. A. A. Blasques, AeroElastic Optimization of a $10 \mathrm{MW}$ Wind Turbine, in: AIAA SciTech - 33rd Wind Energy Symposium. Kissimmee, Florida, USA, 5-9 January 2015.

[24] T. Kim, A. M. Hansen, K. Branner, Development of an anisotropic beam finite element for composite wind turbine blades in multibody system, Journal of Renewable Energy 59 (2013) 172-183. Doi: 10.1016/j.renene.2013.03.033.

[25] F. Vorpahl, M. Strobel, J. M. Jonkman, T. J. Larsen, P. Passon, Verification of aeroelastic offshore wind turbine design codes under IEA wind task XXIII, Journal of Wind Energy (2013). Doi: 10.1002/we.1588.

[26] W. Popko, F. Vorpahl, A. Zuga, M. Kohlmeier, J. Jonkman, A. Robertson, T. J. Larsen, A. Yde, K. Stertr, K. O. et al., Offshore code comparison collaboration continuation (OC4), PHASE I - results of coupled simulations of an offshore wind turbine with jacket support structure, in: Proceedings of the International Offshore and Polar Engineering Conference 2012, pp. 337-346. Rhodes, Greece, 17-23 June 2012.

[27] T. J. Larsen, H. A. Madsen, G. C. Larsen, K. S. Hansen, Validation of the dynamic wake meander model for loads and power production in the Egmond Aan Zee wind farm, Journal of Wind Energy 16(4) (2013) 605-624. Doi: 10.1002/we.1563.

[28] C. Bak, F. Zahle, R. Bitsche, T. Kim, A. Yde, L. C. Henriksen, A. Natarajan, M. H. Hansen, Description of the DTU 10 MW Reference Wind Turbine, DTU Wind Energy, Technical Report-I-0092, Roskilde, Denmark, July 2013.

[29] M. H. Hansen, L. C. Henriksen, Basic DTU Wind Energy Controller, DTU Wind Energy, Technical Report-E-0018, Roskilde, Denmark, 2013. 
[30] C. Pavese, T. Kim, Implementation of Passive Control Strategies through Swept Blades, in: 10th PhD Seminar on Wind Energy in Europe. Orleans, France, 28-31 October 2014.

[31] C. Pavese, C. Tibaldi, T. Kim, Study on Controller Tuning of Wind Turbines with Backward Swept Blades, in: AIAA SciTech - 33rd Wind Energy Symposium. Kissimmee, Florida, USA, 5-9 January 2015.

[32] M. H. Hansen, T. J. Larsen, S. Ø. ye, N. Sørensen, P. Fuglsang, Control Design for a pitch-regulated, variable speed wind turbine, Ris $\emptyset$ National Laboratory, Technical Report Risø-R-1500(EN), Roskilde, Denmark, 2013.

[33] C. Tibaldi, L. C. Henriksen, M. H. Hansen, C. Bak, Effects of gain-scheduling methods in a classical wind turbine controller on wind turbine aeroservoelastic modes and loads, in: Proceedings of the 52th AIAA Aerospace Sciences Meeting. National Harbor, Maryland, USA, 12-17 January 2014.

[34] M. H. Hansen, K. Thomsen, A. Natarajan, A. Barlas, Design Load Basis for onshore turbines - Revision 00, DTU Wind Energy, Technical Report E-0074(EN), Roskilde, Denmark, 2015.

[35] I. E. Commission, International Standard, IEC 61400-1 Third Edition 2005-08, Wind Turbines - Part 1: Design Requirements, Reference Number IEC 61400-1:2005(EN), 2005.

[36] G. Lloyd, Guideline for the Certification of Wind Turbines, Standard, July 2010. 